\title{
Analisa Postur Kerja Operator Bagian Finishing Menggunakan Metode Ovako Work Analysis System (OWAS) di CV. Sarana Teknik
}

\section{Work Posture Analysis for Finishing Operators Using the Ovako Work Analysis System (OWAS) Method at CV. Sarana Teknik}

\author{
Dian F. Hidayat ${ }^{1}$, dan Miftahudin ${ }^{2}$ \\ Teknik Industri, Fakultas Teknik, Universitas Muhammadiyah Tangerang \\ E-mail: dianfriana@gmail.com ${ }^{1}$, niduhatfim790@ gmail.com ${ }^{2}$
}

\begin{abstract}
The purpose of study is analysis the work posture of the finishing section on the CV. Sarana Teknik, in order to reduce musculoskeletal disorders using the Nordic Body Map, and the Ovako Work Analysis System (OWAS). CV. Sarana Teknik is an industry engaged in processing plastic pellets into various products on demand. These products are medicine caps and toys that are relatively small in size. The study was conducted in the finishing section with 6 operators. Based on the Nordic Body Map questionnaire, $49 \%$ of workers or 3 of 6 workers stated that they were somewhat sick to the point where they were examined at 28 points of the body. Then the work attitude analysis that defines the movement of body parts of the back, arms, legs and weight lifted using the Ovako Work Analysis System (OWAS). The results of this study are the body part is very painful, which is dominantly felt by all operators, is back by $100 \%$. The observed work posture is the taking and tidying posture, the result of the analysis is the taking work posture is category 2 which is a dangerous attitude on the musculoskeletal system which results in a significant tension effect so that the posture needs improvement. As for the tidying work posture, category 1 is an attitude that has no problems so this attitude does not need to be improved.
\end{abstract}

Keywords: Ergonomics, Work Posture, Nordic Body Map, Ovako Work Analysis System

\begin{abstract}
ABSTRAK
Tujuan pada penelitian ini adalah menganalisa postur kerja operator bagian finishing pada CV. Sarana Teknik, guna mengurangi gangguan musculoskeletal menggunakan Nordic Body Map, dan Ovako Work Analysis System (OWAS). CV. Sarana teknik adalah industri yang bergerak dibidang pengolahan biji plastik menjadi berbagai produk sesuai permintaan. Produk tersebut adalah tutup obat dan mainan yang berukuran relatif kecil. Penelitian dilakukan pada bagian finishing dengan 6 operator. Berdasarkan kuesioner Nordic Body Map bahwa 49\% pekerja atau 3 dari 6 pekerja menyatakan agak sakit hingga sakit pada 28 titik bagian tubuh yang diperiksa. Kemudian menganalisa sikap kerja yang mendefinisikan pergerakan bagian tubuh punggung, lengan, kaki dan berat beban yang diangkat menggunakan Ovako Work Analysis System (OWAS). Hasil penelitian ini yaitu bagian tubuh sangat sakit yang dominan dirasakan oleh semua operator adalah punggung sebesar $100 \%$. Adapun postur kerja yang diamati adalah postur mengambil dan merapihkan, hasilnya analisa adalah postur kerja mengambil merupakan kategori 2 yaitu sikap berbahaya pada sistem musculoskeletal yang mengakibatkan pengaruh ketegangan yang signifikan sehingga postur tersebut perlu perbaikan. Sedangkan untuk postur kerja merapihkan merupakan kategori 1 yaitu sikap yang tidak memiliki masalah sehingga sikap ini tidak perlu dilakukan perbaikan.
\end{abstract}

Kata kunci: Ergonomi, Postur Kerja, Nordic Body Map, Ovako Work Analysis System

\section{Pendahuluan}

Sebuah kegiatan produksi untuk menghasilkan suatu barang tidak terlepas dari adanya interaksi antara manusia dengan sistem atau mesin produksi. Mesin bekerja untuk 
menghasilkan barang sesuai dengan spesifikasi yang ditentukan, manusia yang mengendalikan mesin agar optimal ketika beroperasi. Adanya interaksi manusia dengan mesin tentu berpengaruh besar terhadap produktifitas sebuah kegiatan produksi, diantaranya karena faktor kinerja mesin yang baik dan rasa aman dan nyaman pada manusianya ketika bekerja. Jika TPM (total preventive maintenance) digunakan untuk merawat kinerja sebuah mesin, maka ergonomi digunakan untuk memberikan rasa aman dan nyaman bagi manusia untuk bekerja.

Menurut Hedge dalam Sugiono, dkk (2018) mendefinisikan ergonomi sebagai ilmu pengetahuan tentang kerja, yang fokus mengatur pada peningkatan kemampuan manusia untuk mendapatkan performansi kerja yang baik. Juga didukung oleh Sanders dan McCormick dalam Sugiono, dkk (2018) yaitu agar semakin produktif, aman, nyaman, dan efektif pada penggunaan oleh manusia, maka ergonomik mempelajari dan menerapkan informasi tentang prilaku manusia, kemampuannya, keterbatasannya serta karakter manusia lainnya guna mendesain suatu peralatan bantu, mesin, aktivitas, pekerjaan, dan lingkungannya. Ergonomi diterapkan di dunia kerja agar manusia merasa aman dan nyaman dalam melakukan pekerjaannya, karena ergonomi memperhatikan bagaimana orang melakukan pekerjaannya, bagaimana posisi dan gerakan tubuh yang digunakan saat bekerja, peralatan yang digunakan serta dampak atau efek yang ditimbulkan bagi kesehatan dan kenyamanan pekerja.

CV. Sarana teknik adalah industri yang bergerak dibidang pengolahan biji plastik menjadi berbagai produk sesuai permintaan pelanggan. Produk yang biasaya diproduksi adalah tutup obat dan mainan yang berukuran relatif kecil. Berkaitan dengan ergonomi pada CV. Sarana Teknik belum memperhatikan hal tersebut. Terutama bagian finishing pada proses handling produk jadi dari hasil cetakan mesin injection dilakukan oleh manusia secara manual. Hal ini dapat dibuktikan dengan hasil observasi awal menggunakan kuesioner Nordic Body Map bahwa $49 \%$ pekerja atau 3 dari 6 pekerja menyatakan agak sakit hingga sakit pada 28 titik bagian tubuh yang diperiksa.

Beberapa penelitian sebelumnya yang menganalisa postur kerja manusia diataranya adalah Anggraeni dan Pratama (2012) pada stasiun pengepakan bandela karet menggunakan metode Ovako Working Analysis System (OWAS) hasilnya adalah 3 postur kerja yang dilakukan oleh operator memiliki resiko cidera yang sama sebesar 33\% sehingga perlu perbaikan secepatnya menggunakan alat bantu pemindahan barang berupa ring conveyor. Penelitian lainnya yaitu Ramdhani dan Zalynda (2017) pada pengrajin Handy Craft menggunakan Nordic Body Map dan Rapid Upper Limp Assessment (RULA) di Kecamatan Purwawinangun, Kabupaten Kuningan, Jawa Barat hasilnya yaitu keluhan yang dirasakan oleh pengrajin Handy Craft terletak pada tubuh bagian leher, punggung, dan pinggang. Sedangkan skor individual artinya skor yang sangat mengalami keluhan pada tiga responden dengan job desk pekerjaanya yaitu pemolaan dan pengukuran. Analisis RULA terhadap pengrajin Handy Craft yang telah dilakukan analisis berdasarakan pengamatan bahwa perubahan postur kerja harus dilakukan secepatnya. Perubahan yang harus segara dilakukan untuk mencegah terjadinya kelelahan postur tubuh yang berkepanjangan maka harus dibuatkan alat bantu kursi dan meja yang ergonomis untuk meminimalisir terjadinya cedera.

Dari beberapa penelitian di atas, dapat diketahui bahwa untuk mengetahui postur kerja operator dapat dilakukan dengan menggunakan metode Ovako Work Analysis System (OWAS). Untuk mengetahui gangguan musculoskeletal digunakan kuesioner Nordic Body Map yang ditujukan kepada pekerja. Menurut Pamula (2012), Ovako Work Analysis System (OWAS) merupakan metode analisis sikap kerja yang mendefinisikan pergerakan bagian tubuh punggung, lengan, kaki dan berat beban yang diangkat. Masing-masing anggota tubuh tersebut diklasifikasikan menjadi sikap kerja. Sikap bagian tubuh yang diamati adalah punggung, lengan, kaki dan berat beban pekerja. Penelitian ini dilakukan dengan dasar keluhan sakit dan pegal pada bagian tubuh operator karena melakukan kegiatan tersebut secara terus-menerus. Besarnya kemungkinan karena postur kerja operator yang belum sesuai dengan ergonomi atau 
fasilitas kerja mereka yang belum sesuai. Sehingga tujuan pada penelitian ini adalah memperbaiki postur kerja operator bagian finishing guna mengurangi gangguan musculoskeletal menggunakan Nordic Body Map, dan Ovako Work Analysis System (OWAS).

\section{Metode Penelitian}

\subsection{Jenis Data}

\subsubsection{Data primer}

Beberapa data berikut ini merupakan data yang diperoleh langsung dari sumbernya yaitu;

a. Data keluhan tenaga kerja

Pengumpulan data keluhan rasa sakit akibat pekerjaan yang dialami oleh pekerja dilakukan dengan pengisian Nordic Body Map. Hasilnya akan menunjukan perbedaan keluhan rasa sakit akibat melakukan pekerjaan. Kemudian, data dihitung dengan menggunakan skala likert untuk mengetahui presentase keluhan pekerja.

b. Data postur kerja

Pengumpulan data postur menggunakan kamera digital, dimana peneliti akan merekam dan mengambil gambar saat aktivitas kerja berlangsung.

\subsubsection{Data sekunder}

Untuk mendukung penelitian, data sekunder diperoleh dari hasil dokumentasi perusahaan, buku referensi, jurnal penelitian dan lainnya yang berkaitan dengan penelitian.

\subsection{Metode Pengolahan dan Analisa Data}

1. Identifikasi Musculoskeletal Disorders (MSDs) menggunakan Nordic Body Map.

Nordic Body Map digunakan untuk menganalisis peta tubuh yang ditunjukkan pada tiap bagian tubuh. Kemudian dapat diketahui bagian-bagian otot yang mengalami keluhan dengan tingkat keluhan mulai dari rasa tidak nyaman (agak sakit) sampai sangat sakit. Berdasarkan hasil analisis peta tubuh dapat diketahui jenis dan tingkat keluhan otot skeletal yang dirasakan oleh pekerja. Metode ini dilakukan dengan memberikan penilaian subjektif pada pekerja (Kusmindari, 2014). Hasil kuisioner Nordic Body Map operator bagian finishing akan diolah dengan langkah-langkah sebagai berikut :

a. Merekapitulasi jawaban kuisioner setiap operator bagian finishing.

b. Menghitung prosentase tiap keluhan yang dialami oleh para operator bagian finishing.

2. Identifikasi postur kerja operator menggunakan Ovako Work Analysis System (OWAS).

Metode ini digunakan untuk menganalisa sikap kerja yang mendefinisikan pergerakan bagian tubuh punggung, lengan, kaki dan berat beban yang diangkat. Masing-masing anggota tubuh tersebut diklasifikasikan menjadi sikap kerja. Sikap bagian tubuh yang diamati adalah punggung, lengan, kaki dan berat beban pekerja (Pamula, 2012). Tahap ini menganalisa postur pekerja dengan memperhatikan syarat berikut:

a. Sikap Punggung: lurus, membungkuk, memutar atau miring kesamping, membungkuk dan memutar atau membungkuk kedepan dan menyamping.

b. Sikap Lengan: kedua lengan berada dibawah bahu, satu lengan berada pada atau diatas bahu, kedua lengan pada atau diatas bahu.

c. Sikap Kaki: duduk, berdiri bertumpu pada kedua kaki lurus, berdiri bertumpu pada satu kaki lurus, berdiri bertumpu pada kedua kaki dengan lutut ditekuk, berdiri bertumpu pada satu kaki dengan lutut ditekuk, berlutut pada satu atau kedua lutut, berjalan.

d. Berat Beban: kurang dari $10 \mathrm{Kg}(\mathrm{W}=10 \mathrm{Kg}), 10 \mathrm{Kg}-20 \mathrm{Kg}(10 \mathrm{Kg}<\mathrm{W} \leq 20 \mathrm{Kg})$, berat beban adalah lebih besar dari $20 \mathrm{Kg}(\mathrm{W}>20 \mathrm{Kg}$ ). 


\section{Hasil dan Pembahasan}

\subsection{Kuesioner Nordic Body Map}

Analisa peta tubuh yang ditunjukkan menggunakan Nordic Body Map untuk dapat diketahui jenis dan tingkat keluhan otot skeletal yang mengalami keluhan dengan tingkat keluhan mulai dari rasa tidak sakit sampai sangat sakit. Pada table 1 merupakan hasil kuisioner dengan prosentasi masing-masing, yaitu;

Tabel 1. Hasil Kuisioner Nordic Body Map

\begin{tabular}{|c|c|c|c|c|c|c|c|c|c|c|c|}
\hline \multirow{3}{*}{ No. } & \multirow{3}{*}{ Jenis Keluhan } & \multicolumn{8}{|c|}{ Responden } & \multirow{2}{*}{\multicolumn{2}{|c|}{ Jumlah }} \\
\hline & & \multicolumn{2}{|c|}{ Tidak Sakit } & \multicolumn{2}{|c|}{ Agak Sakit } & \multicolumn{2}{|c|}{ Sakit } & \multicolumn{2}{|c|}{ Sakit Sekali } & & \\
\hline & & Opr. & $\%$ & Opr. & $\%$ & Opr. & $\%$ & Opr. & $\%$ & Opr. & $\%$ \\
\hline 1 & Sakit pada bagian leher atas & 0 & $0 \%$ & 4 & $67 \%$ & 2 & $33 \%$ & 0 & $0 \%$ & 6 & $100 \%$ \\
\hline 2 & Sakit pada bagian leher bawah & 1 & $17 \%$ & 3 & $50 \%$ & 2 & $33 \%$ & 0 & $0 \%$ & 6 & $100 \%$ \\
\hline 3 & sakit pada bagian bahu kiri & 0 & $0 \%$ & 1 & $17 \%$ & 2 & $33 \%$ & 3 & $50 \%$ & 6 & $100 \%$ \\
\hline 4 & sakit pada bagian bahu kanan & 0 & $0 \%$ & 3 & $50 \%$ & 2 & $33 \%$ & 1 & $17 \%$ & 6 & $100 \%$ \\
\hline 5 & sakit pada bagian lengan atas kiri & 3 & $50 \%$ & 3 & $50 \%$ & 0 & $0 \%$ & 0 & $0 \%$ & 6 & $100 \%$ \\
\hline 6 & sakit pada bagian punggung & 0 & $0 \%$ & 0 & $0 \%$ & 0 & $0 \%$ & 6 & $100 \%$ & 6 & $100 \%$ \\
\hline 7 & sakit pada bagian lengan atas kanan & 0 & $0 \%$ & 3 & $50 \%$ & 3 & $50 \%$ & 0 & $0 \%$ & 6 & $100 \%$ \\
\hline 8 & sakit pada bagian pinggang & 0 & $0 \%$ & 0 & $0 \%$ & 1 & $17 \%$ & 5 & $83 \%$ & 6 & $100 \%$ \\
\hline 9 & sakit pada bagian bawah pinggang & 3 & $50 \%$ & 2 & $33 \%$ & 1 & $17 \%$ & 0 & $0 \%$ & 6 & $100 \%$ \\
\hline 10 & sakit pada bagian bokong & 5 & $83 \%$ & 1 & $17 \%$ & 0 & $0 \%$ & 0 & $0 \%$ & 6 & $100 \%$ \\
\hline 11 & sakit pada bagian siku kiri & 5 & $83 \%$ & 1 & $17 \%$ & 0 & $0 \%$ & 0 & $0 \%$ & 6 & $100 \%$ \\
\hline 12 & sakit pada bagian siku kanan & 4 & $67 \%$ & 2 & $33 \%$ & 0 & $0 \%$ & 0 & $0 \%$ & 6 & $100 \%$ \\
\hline 13 & sakit pada bagian lengan bawah kiri & 3 & $50 \%$ & 3 & $50 \%$ & 0 & $0 \%$ & 0 & $0 \%$ & 6 & $100 \%$ \\
\hline 14 & sakit pada bagian lengan bawah kanan & 3 & $50 \%$ & 3 & $50 \%$ & 0 & $0 \%$ & 0 & $0 \%$ & 6 & $100 \%$ \\
\hline 15 & sakit pada bagian pergelangan tangan kiri & 0 & $0 \%$ & 4 & $67 \%$ & 2 & $33 \%$ & 0 & $0 \%$ & 6 & $100 \%$ \\
\hline 16 & sakit pada bagian pergelangan tangan kanan & 0 & $0 \%$ & 2 & $33 \%$ & 4 & $67 \%$ & 0 & $0 \%$ & 6 & $100 \%$ \\
\hline 17 & sakit pada bagian tangan kiri & 0 & $0 \%$ & 4 & $67 \%$ & 2 & $33 \%$ & 0 & $0 \%$ & 6 & $100 \%$ \\
\hline 18 & sakit pada bagian tangan kanan & 0 & $0 \%$ & 5 & $83 \%$ & 1 & $17 \%$ & 0 & $0 \%$ & 6 & $100 \%$ \\
\hline 19 & sakit pada bagian paha kiri & 3 & $50 \%$ & 3 & $50 \%$ & 0 & ०\% & 0 & $0 \%$ & 6 & $100 \%$ \\
\hline 20 & sakit pada bagian paha kanan & 3 & $50 \%$ & 3 & $50 \%$ & 0 & $0 \%$ & 0 & $0 \%$ & 6 & $100 \%$ \\
\hline 21 & sakit pada bagian lutut kiri & 4 & $67 \%$ & 2 & $33 \%$ & 0 & $0 \%$ & 0 & $0 \%$ & 6 & $100 \%$ \\
\hline 22 & sakit pada bagian lutut kanan & 4 & $67 \%$ & 2 & $33 \%$ & 0 & $0 \%$ & 0 & $0 \%$ & 6 & $100 \%$ \\
\hline 23 & sakit pada bagian betis kiri & 5 & $83 \%$ & 1 & $17 \%$ & 0 & $0 \%$ & 0 & $0 \%$ & 6 & $100 \%$ \\
\hline 24 & sakit pada bagian betis kanan & 5 & $83 \%$ & 1 & $17 \%$ & 0 & $0 \%$ & 0 & $0 \%$ & 6 & $100 \%$ \\
\hline 25 & sakit pada pergelangan kaki kiri & 6 & $100 \%$ & 0 & $0 \%$ & 0 & $0 \%$ & 0 & $0 \%$ & 6 & $100 \%$ \\
\hline 26 & sakit pada pergelangan kaki kanan & 6 & $100 \%$ & 0 & $0 \%$ & 0 & $0 \%$ & 0 & $0 \%$ & 6 & $100 \%$ \\
\hline 27 & sakit pada bagian telapak kaki kiri & 4 & $67 \%$ & 2 & $33 \%$ & 0 & $0 \%$ & 0 & $0 \%$ & 6 & $100 \%$ \\
\hline 28 & sakit pada bagian telapak kaki kanan & 4 & $67 \%$ & 2 & $33 \%$ & 0 & $0 \%$ & 0 & $0 \%$ & 6 & $100 \%$ \\
\hline
\end{tabular}

Berdasarkan tabel diatas yaitu dapat disimpulkan bahwa prosentasi terbesar untuk keluhan tidak sakit yaitu bagian pergelangan kaki kiri dan kaki kanan masing-masing sebesar $100 \%$, keluhan agak sakit pada bagian tangan kanan sebesar 83\%, keluhan sakit pada bagian pergelangan tangan kanan sebesar $67 \%$, dan keluhan sakit sekali pada bagian punggung sebesar $100 \%$.

\subsection{Analisa postur kerja dengan Ovako Work Analysis System (OWAS).}

Analisa sikap kerja yang mendefinisikan pergerakan bagian tubuh punggung, lengan, kaki dan berat beban yang diangkat. Masing-masing pergerakan memiliki syarat sebagai penilaian pada gerak tubuh yang diamati.

Tabel 2. Penilaian sikap punggung (back)

\begin{tabular}{cl}
\hline Kode & \multicolumn{1}{c}{ Keterangan } \\
\hline 1 & Lurus \\
2 & Membungkuk \\
3 & Memutar atau miring kesamping \\
4 & Membungkuk dan memutar atau membungkuk \\
& kedepan dan menyamping \\
\hline \multicolumn{2}{c}{ Tabel 3. Penilaian sikap lengan (arm $)$} \\
\hline Kode & \multicolumn{1}{c}{ Keterangan } \\
\hline 1 & Kedua lengan berada dibawah bahu \\
3 & Satu lengan berada pada atau diatas bahu \\
\hline
\end{tabular}


Tabel 4. Penilaian sikap kaki (leg)

\begin{tabular}{cl}
\hline Kode & \multicolumn{1}{c}{ Keterangan } \\
\hline 1 & Duduk \\
2 & Berdiri bertumpu pada kedua kaki lurus \\
3 & Berdiri bertumpu pada satu kaki lurus \\
4 & Berdiri bertumpu pada kedua kaki dengan lutut \\
& ditekuk \\
5 & Berdiri bertumpu pada satu kaki dengan lutut ditekuk \\
6 & Berlutut pada satu atau kedua lutut \\
7 & Berjalan \\
\hline
\end{tabular}

Tabel 5. Penilaian berat beban (load)

\begin{tabular}{cl}
\hline Kode & \multicolumn{1}{c}{ Keterangan } \\
\hline 1 & Kurang dari $10 \mathrm{Kg}(\mathrm{W}=10 \mathrm{Kg})$ \\
2 & $10 \mathrm{Kg}-20 \mathrm{Kg}(10 \mathrm{Kg}<\mathrm{W}=20 \mathrm{Kg})$ \\
3 & Lebih besar dari $20 \mathrm{Kg}(\mathrm{W}>20 \mathrm{Kg})$ \\
\hline
\end{tabular}

A. Analisa postur kerja mengambil

Aktifitas mengambil terjadi pada saat operator mengambil produk berupa tutup obat setiap 20 detik yang dihasilkan oleh mesin injection.

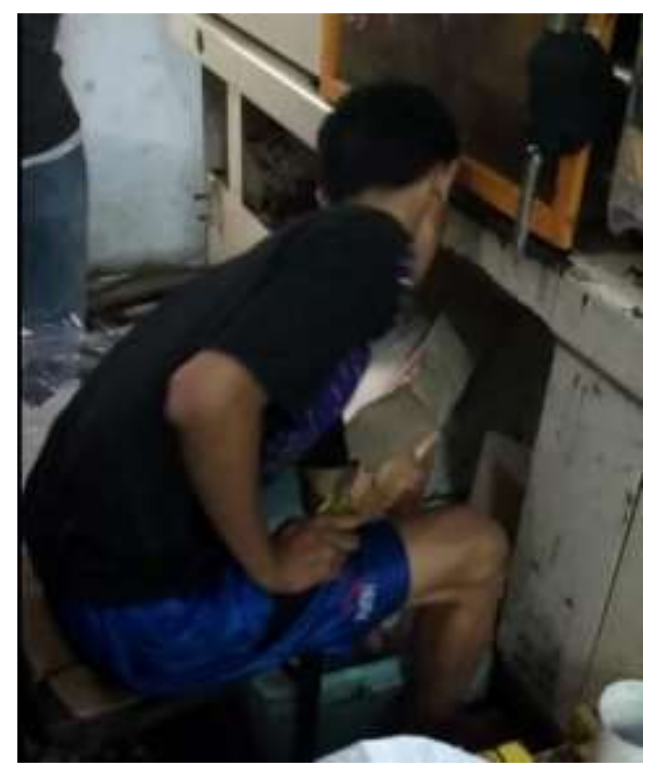

Gambar 1. Postur Kerja Mengambil

Tabel 6. Penilaian OWAS Postur Kerja Mengambil 


\begin{tabular}{|c|c|c|c|c|c|c|c|c|c|c|c|c|c|c|c|c|c|c|c|c|c|c|}
\hline \multirow{4}{*}{$\begin{array}{c}\text { Sikap } \\
\text { Punggung } \\
\text { (Back) }\end{array}$} & \multirow{4}{*}{$\begin{array}{c}\text { Sikap } \\
\text { Tangan } \\
(\text { Arm) }\end{array}$} & \multicolumn{21}{|c|}{ Sikap Kaki (Leg) } \\
\hline & & \multicolumn{3}{|c|}{1} & \multicolumn{3}{|c|}{2} & \multicolumn{3}{|c|}{3} & \multicolumn{3}{|c|}{4} & \multicolumn{3}{|c|}{5} & \multicolumn{3}{|c|}{6} & \multicolumn{3}{|c|}{7} \\
\hline & & \multicolumn{3}{|c|}{$\begin{array}{c}\text { Berat Beban } \\
\text { (Load) }\end{array}$} & \multicolumn{3}{|c|}{$\begin{array}{c}\text { Berat Beban } \\
(\text { Load })\end{array}$} & \multicolumn{3}{|c|}{$\begin{array}{l}\text { Berat Beban } \\
\text { (Load) }\end{array}$} & \multicolumn{3}{|c|}{$\begin{array}{c}\text { Berat Beban } \\
\text { (Load) }\end{array}$} & \multicolumn{3}{|c|}{$\begin{array}{c}\text { Berat Beban } \\
\text { (Load) }\end{array}$} & \multicolumn{3}{|c|}{$\begin{array}{c}\text { Berat Beban } \\
(\text { Load })\end{array}$} & \multicolumn{3}{|c|}{$\begin{array}{c}\text { Berat Beban } \\
(\text { Load })\end{array}$} \\
\hline & & 1 & 2 & 3 & 1 & 2 & 3 & 1 & 2 & 3 & 1 & 2 & 3 & 1 & 2 & 3 & 1 & 2 & 3 & 1 & 2 & 3 \\
\hline \multirow{3}{*}{1} & 1 & 1 & 1 & 1 & 1 & 1 & 1 & 1 & 1 & 1 & 2 & 2 & 2 & 2 & 2 & 2 & 1 & 1 & 1 & 1 & 1 & 1 \\
\hline & 2 & 1 & 1 & 1 & 1 & 1 & 1 & 1 & 1 & 1 & 2 & 2 & 2 & 2 & 2 & 2 & 1 & 1 & 1 & 1 & 1 & 1 \\
\hline & 3 & 1 & 1 & 1 & 1 & 1 & 1 & 1 & 1 & 1 & 2 & 2 & 3 & 2 & 2 & 3 & 1 & 1 & 1 & 1 & 1 & 2 \\
\hline \multirow{3}{*}{2} & 1 & (2) & 2 & 3 & 2 & 2 & 3 & 2 & 2 & 3 & 3 & 3 & 3 & 3 & 3 & 3 & 2 & 2 & 2 & 2 & 3 & 3 \\
\hline & 2 & 2 & 2 & 3 & 2 & 2 & 3 & 2 & 3 & 3 & 3 & 4 & 4 & 3 & 4 & 4 & 3 & 3 & 4 & 2 & 3 & 4 \\
\hline & 3 & 3 & 3 & 4 & 2 & 2 & 3 & 3 & 3 & 3 & 3 & 4 & 4 & 4 & 4 & 4 & 4 & 4 & 4 & 2 & 3 & 4 \\
\hline \multirow{3}{*}{3} & 1 & 1 & 1 & 1 & 1 & 1 & 1 & 1 & 1 & 2 & 3 & 3 & 3 & 4 & 4 & 4 & 1 & 1 & 1 & 1 & 1 & 1 \\
\hline & 2 & 2 & 2 & 3 & 1 & 1 & 1 & 1 & 1 & 2 & 4 & 4 & 4 & 4 & 4 & 4 & 3 & 3 & 3 & 1 & 1 & 1 \\
\hline & 3 & 2 & 2 & 3 & 1 & 1 & 1 & 2 & 3 & 3 & 4 & 4 & 4 & 4 & 4 & 4 & 4 & 4 & 4 & 1 & 1 & 1 \\
\hline \multirow{3}{*}{4} & 1 & 2 & 3 & 3 & 2 & 2 & 3 & 2 & 2 & 3 & 4 & 4 & 4 & 4 & 4 & 4 & 4 & 4 & 4 & 2 & 3 & 4 \\
\hline & 2 & 3 & 3 & 4 & 2 & 3 & 4 & 3 & 3 & 4 & 4 & 4 & 4 & 4 & 4 & 4 & 4 & 4 & 4 & 2 & 3 & 4 \\
\hline & 3 & 4 & 4 & 4 & 2 & 3 & 4 & 3 & 3 & 4 & 4 & 4 & 4 & 4 & 4 & 4 & 4 & 4 & 4 & 2 & 3 & 4 \\
\hline
\end{tabular}

Berdasarkan penilaian postur kerja mengambil yang dapat dilihat pada tabel 6 , maka sikap mengambil merupakan kategori 2 yaitu sikap berbahaya pada sistem musculoskeletal yang mengakibatkan pengaruh ketegangan yang signifikan sehingga postur tersebut perlu perbaikan. Kategori 2 diperoleh berdasarkan penilaian sikap punggung membungkuk (kode 2), sikap tangan yaitu kedua lengan berada dibawah bahu (kode 1), sikap kaki duduk (kode 1) dan berat beban yang terjadi kurang dari $10 \mathrm{Kg}$ (kode 1$)$.

B. Analisa postur kerja merapihkan

Aktifitas merapihkan adalah merapihkan produk dengan memotong sisa cetakan agar produk tersebut menjadi lebih baik.

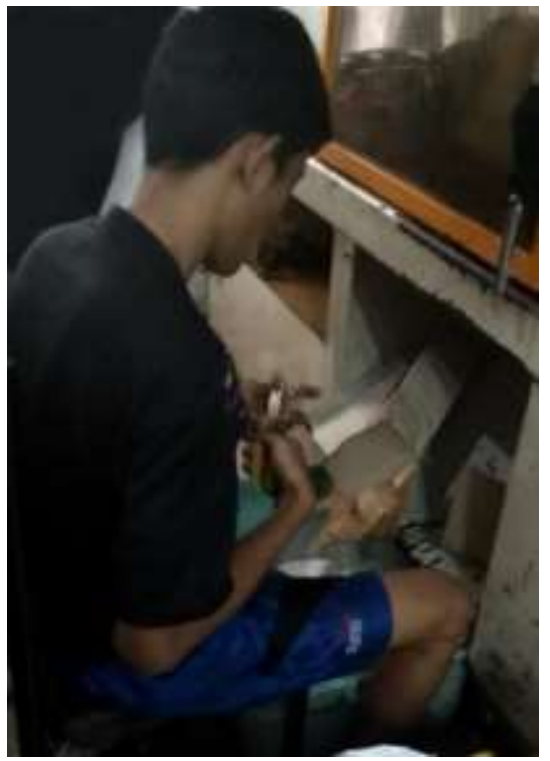

Gambar 2. Postur Kerja Merapihkan 
Tabel 7. Penilaian OWAS Postur Kerja Mengambil

\begin{tabular}{|c|c|c|c|c|c|c|c|c|c|c|c|c|c|c|c|c|c|c|c|c|c|c|}
\hline \multirow{4}{*}{$\begin{array}{c}\text { Sikap } \\
\text { Punggung } \\
\text { (Back) }\end{array}$} & \multirow{4}{*}{$\begin{array}{c}\text { Sikap } \\
\text { Tangan } \\
(\text { Arm) }\end{array}$} & \multicolumn{21}{|c|}{ Sikap Kaki (Leg) } \\
\hline & & \multicolumn{3}{|c|}{1} & \multicolumn{3}{|c|}{2} & \multicolumn{3}{|c|}{3} & \multicolumn{3}{|c|}{4} & \multicolumn{3}{|c|}{5} & \multicolumn{3}{|c|}{6} & \multicolumn{3}{|c|}{7} \\
\hline & & \multicolumn{3}{|c|}{$\begin{array}{c}\text { Berat Beban } \\
\text { (Load) }\end{array}$} & \multicolumn{3}{|c|}{$\begin{array}{c}\text { Berat Beban } \\
\text { (Load) }\end{array}$} & \multicolumn{3}{|c|}{$\begin{array}{c}\text { Berat Beban } \\
(\text { Load })\end{array}$} & \multicolumn{3}{|c|}{$\begin{array}{c}\text { Berat Beban } \\
(\text { Load })\end{array}$} & \multicolumn{3}{|c|}{$\begin{array}{c}\text { Berat Beban } \\
(\text { Load })\end{array}$} & \multicolumn{3}{|c|}{$\begin{array}{c}\text { Berat Beban } \\
(\text { Load })\end{array}$} & \multicolumn{3}{|c|}{$\begin{array}{c}\text { Berat Beban } \\
(\text { Load })\end{array}$} \\
\hline & & 1 & 2 & 3 & 1 & 2 & 3 & 1 & 2 & 3 & 1 & 2 & 3 & 1 & 2 & 3 & 1 & 2 & 3 & 1 & 2 & 3 \\
\hline \multirow{3}{*}{1} & 1 & (1) & 1 & 1 & 1 & 1 & 1 & 1 & 1 & 1 & 2 & 2 & 2 & 2 & 2 & 2 & 1 & 1 & 1 & 1 & 1 & 1 \\
\hline & 2 & 1 & 1 & 1 & 1 & 1 & 1 & 1 & 1 & 1 & 2 & 2 & 2 & 2 & 2 & 2 & 1 & 1 & 1 & 1 & 1 & 1 \\
\hline & 3 & 1 & 1 & 1 & 1 & 1 & 1 & 1 & 1 & 1 & 2 & 2 & 3 & 2 & 2 & 3 & 1 & 1 & 1 & 1 & 1 & 2 \\
\hline \multirow{3}{*}{2} & 1 & 2 & 2 & 3 & 2 & 2 & 3 & 2 & 2 & 3 & 3 & 3 & 3 & 3 & 3 & 3 & 2 & 2 & 2 & 2 & 3 & 3 \\
\hline & 2 & 2 & 2 & 3 & 2 & 2 & 3 & 2 & 3 & 3 & 3 & 4 & 4 & 3 & 4 & 4 & 3 & 3 & 4 & 2 & 3 & 4 \\
\hline & 3 & 3 & 3 & 4 & 2 & 2 & 3 & 3 & 3 & 3 & 3 & 4 & 4 & 4 & 4 & 4 & 4 & 4 & 4 & 2 & 3 & 4 \\
\hline \multirow{3}{*}{3} & 1 & 1 & 1 & 1 & 1 & 1 & 1 & 1 & 1 & 2 & 3 & 3 & 3 & 4 & 4 & 4 & 1 & 1 & 1 & 1 & 1 & 1 \\
\hline & 2 & 2 & 2 & 3 & 1 & 1 & 1 & 1 & 1 & 2 & 4 & 4 & 4 & 4 & 4 & 4 & 3 & 3 & 3 & 1 & 1 & 1 \\
\hline & 3 & 2 & 2 & 3 & 1 & 1 & 1 & 2 & 3 & 3 & 4 & 4 & 4 & 4 & 4 & 4 & 4 & 4 & 4 & 1 & 1 & 1 \\
\hline \multirow{3}{*}{4} & 1 & 2 & 3 & 3 & 2 & 2 & 3 & 2 & 2 & 3 & 4 & 4 & 4 & 4 & 4 & 4 & 4 & 4 & 4 & 2 & 3 & 4 \\
\hline & 2 & 3 & 3 & 4 & 2 & 3 & 4 & 3 & 3 & 4 & 4 & 4 & 4 & 4 & 4 & 4 & 4 & 4 & 4 & 2 & 3 & 4 \\
\hline & 3 & 4 & 4 & 4 & 2 & 3 & 4 & 3 & 3 & 4 & 4 & 4 & 4 & 4 & 4 & 4 & 4 & 4 & 4 & 2 & 3 & 4 \\
\hline
\end{tabular}

Berdasarkan penilaian postur kerja merapihkan yang dapat dilihat pada tabel 7, maka sikap merapihkan merupakan kategori 1 yaitu sikap yang tidak memiliki masalah. Kategori 1 diperoleh berdasarkan penilaian sikap punggung lurus (kode 1), sikap tangan yaitu kedua lengan berada dibawah bahu (kode 1), sikap kaki duduk (kode 1) dan berat beban yang terjadi kurang dari $10 \mathrm{Kg}$ (kode 1).

\section{Kesimpulan dan Saran}

\subsection{Kesimpulan}

Berdasarkan hasil analisa dan pembahasan maka dapat disimpulkan sebagai berikut, yaitu;

a. Hasil kuisioner menggunakan Nordic Body Map diperoleh bagian tubuh yang terasa sangat sakit menurut 6 operator finishing adalah bagian punggung. Nilai ini diperoleh berdasarkan nilai prosentasi terbesar yaitu $100 \%$.

b. Terdapat 2 postur kerja yang diamati yaitu postur kerja mengambil dan merapihkan, dengan Ovako Work Analysis System (OWAS) diperoleh hasil bahwa postur kerja mengambil merupakan kategori 2 yaitu sikap berbahaya pada sistem musculoskeletal yang mengakibatkan pengaruh ketegangan yang signifikan sehingga postur tersebut perlu perbaikan. Sedangkan untuk postur kerja merapihkan merupakan kategori 1 yaitu sikap yang tidak memiliki masalah sehingga sikap ini tidak perlu dilakukan perbaikan.

\subsection{Saran}

Berdasarkan hasil penelitian, perlunya desain tempat kerja untuk membantu operator dalam melakukan pekerjaan agar tidak ada keluhan, terutama pada bagian finishing dengan postur kerja mengambil dapat diperbaiki sehingga diharapkan produktifitas dapat meningkat karena operator merasa nyaman dengan pekerjaannya.

\section{DAFTAR PUSTAKA}

Anggraini, W. dan Pratama, A. M. 2012. Analisis Postur Kerja Dengan Menggunakan Metode Ovako Working Analysis System (OWAS) Pada Stasiun Pengepakan Bandela Karet (Studi Kasus di PT. Riau

Crumb Rubber Factory Pekanbaru). Jurnal Sains, Teknologi dan Industri. 10 (1), pp. $10-18$.

Kusmindari, Ch D. Oktaviana, R. Yuliwati, E. 2014. Desain Dayan Ergonomis Untuk Mengurangi Musculoskeletal Disorder Pada Pengrajin Songket Dengan 
Menggunakan Aplikasi Nordic Body Map. Seminar Nasional Teknik Industri BKSTI

Pamula, A. R. 2012. Analisis Postur Kerja Pada Aktivitas Manual Material Handling Dengan Menggunakan Metode Penilaian Ovako Work Analisis System (OWAS) Pada Pekerja Unit di PT. X Wilayah Semarang. Skripsi Fakultas Kesehatan Masyarakat.

Ramdhani, D. Zalynda, P. M. 2017. Analisis Postur Kerja Pengrajin Handycraft Menggunakan Nordic Body Map Dan Metode Rapid Upper Limb Assessment (RULA). Jurnal Teknik Industri, Program Studi Teknik Industri, Fakultas Teknik, Universitas Pasundan.

Sugiono, Putro, W. W., Sari, S. I. K. 2018. Ergonomi Untuk Pemula (Prinsip Dasar \& Aplikasinya). Malang: UB Press. 